\title{
Production of Transparent Conducting ZnO Thin Films with Preheated Temperature by Sol-Gel Spin Coating Technique
}

\author{
S. Rajesh ${ }^{1}$, K. Saravanakumar², T. Jayakumar'3, V. Kathiravan*4, S. Praburaj ${ }^{5}$, \\ M. Aasha 6 \\ 1 Department of Physics, Pachaiyappas college for men, Kanchipuram- 631 501, Tamil Nadu, India. \\ ${ }^{2}$ Department of Physics, Mahendra Engineering College (Autonomous), Namakkal, 637503, Tamil Nadu, India. \\ ${ }^{3}$ Department of Physics, Government Arts College (Autonomous), Kumbakonam-612001, Tamil Nadu, India. \\ 4,5,6Department of Physics, Annai College of Arts \& Science, Kovilacheri, Kumbakonam- 612 503, Tamil Nadu, India.
}

\begin{abstract}
To date, thin film deposition with low cost technique and desired process parameters has been intensively studied. The cost effective sol-gel spin coating has been widely used for the deposition of different types of elements in thin film form. ZnO thin films can also deposit with the application of this technique. The prepared solution led to deposit high crystalline ZnO thin films without annealing at elevated temperature. The crystal structure of deposited films was characterized by X-ray diffraction technique. Narrowed and high intensity diffraction peak at $34.4^{\circ}$ clearly indicated that the films exhibit hexagonal wrutzite structure of $\mathrm{ZnO}$. The optical properties of these films were typically studi ed using UVvis NIR double beam spectrophometer, the optical transmittance in the visible region was more than $90 \%$ and showed sharp absorption edge. SEM images showed earth warm like wrinkle surface. The four probe method revealed electrical resistivity of $1.4 \Omega \mathrm{cm}$.
\end{abstract}

KEYWORDS: Sol-gel deposition, ZnO film, structural, optical, electrical properties.

\section{INTRODUCTION}

In recent past, $\mathrm{ZnO}$ thin films have been received increasing attention for arrays of applications in optoelectronics device such as transparent electrode for solar cell [1], light emitting diodes [2], flat panel displays [3]. $\mathrm{ZnO}$ has wide band gap (3.37 eV) with high excitonic binding energy $(60 \mathrm{meV})$ and n-type conductivity $[4,5]$; these peculiar properties exhibit high transmittance in visible region and high electrical conductivity. Besides, $\mathrm{ZnO}$ is a low-cost, non-toxic, high chemical and thermal stability [6-9]. Several methods have been employed for deposition of $\mathrm{ZnO}$ thin films such as sputtering, spray pyrolysis, pulsed laser deposition (PLD) and sol-gel processing. Of these methods, sol-gel has attracted interest for depositing thin films because of its significant advantages: simplicity, inexpensive, large area coating and ease dope.

In sol-gel deposition, most of the researchers are found amorphous $\mathrm{ZnO}$ films before post annealing treatment. To get high quality ZnO films after as-prepared, the films were annealed at high temperatures. Kumar et al. [10] reported the sol-gel deposited films are in amorphous state, which are transformed into crystalline state during the annealing process. $\mathrm{Bu}$ et al. [11] reported that the coated films were sintered in two step process. Initially, the film was sintered at $250{ }^{\circ} \mathrm{C}$ to evaporate the solvent and then annealed at $550{ }^{\circ} \mathrm{C}$ to crystallite the film. There are no studies on $\mathrm{ZnO}$ film properties in literature for asprepared film, because of the poor in crystalline nature of films before annealing. In the present work, therefore, we concentrated to deposit high crystalline quality $\mathrm{ZnO}$ thin films with good optical transmittance without the post annealing treatment. The films deposited at preheated temperature of $200{ }^{\circ} \mathrm{C}$ were studied their structural, optical and surface morphology properties and reported.

\section{EXPERIMENTAL}

\subsection{Deposition of thin films}

Un-doped $\mathrm{ZnO}$ and $\mathrm{F}$ doped $\mathrm{ZnO}$ thin films were deposited by a sol-gel technique. The host and dopant materials were zinc acetate dehydrate $\left(\mathrm{C}_{4} \mathrm{H}_{10} \mathrm{O}_{6} \mathrm{Zn}\right)$ and ammonium fluoride $\left(\mathrm{NH}_{4} \mathrm{~F}\right)$, respectively. Ethanol was used as solvent and monoethanol amine (MEA) was used as stabilizer. For the preparation of starting precursor, $0.1 \mathrm{M}$ of zinc acetate dihydrate and $0.1 \mathrm{M}$ of ammonium fluoride (5 at. \%) were dissolved in combining of $19 \mathrm{~mL}$ ethanol and $1 \mathrm{~mL}$ of monoethylene amine. This solution was stirred at $60{ }^{\circ} \mathrm{C}$ for $2 \mathrm{~h}$ to get clear and homogeneous solution, while solution container was wrapped tightly with aluminum foil to avoid the evaporation of solvent, which maintaining the appropriate viscous of solution. Then the solutions were aged for $24 \mathrm{~h}$ at room temperature. The glass substrates were immersed in the diluted $\mathrm{HCl}$ for $2 \mathrm{~h}$ to etch dust particle if any on surface to be coated and then subjected to the ultrasonic waves and then thoroughly cleaned with acetone. The precursor solution was dropped on to the glass substrate, which was rotate at the speed of $5000 \mathrm{rpm}$ for $60 \mathrm{~s}$ by a spin coater. After the coating, the film was preheated at $200{ }^{\circ} \mathrm{C}$ for $10 \mathrm{~min}$ to evaporate the solvent and organic residuals as well as for

*Corresponding Author: kathiravan626@gmail.com

Received: 19.01.2019 Accepted: 18.02.2019 Published on: 27.02.2019

Rajesh et al., 
the crystallization of $\mathrm{ZnO}$. The coating procedures have been repeated for 10 cycles to get a quality film. The flow chart of ZnO thin film preparation by sol-gel technique is shown in Figure 1.

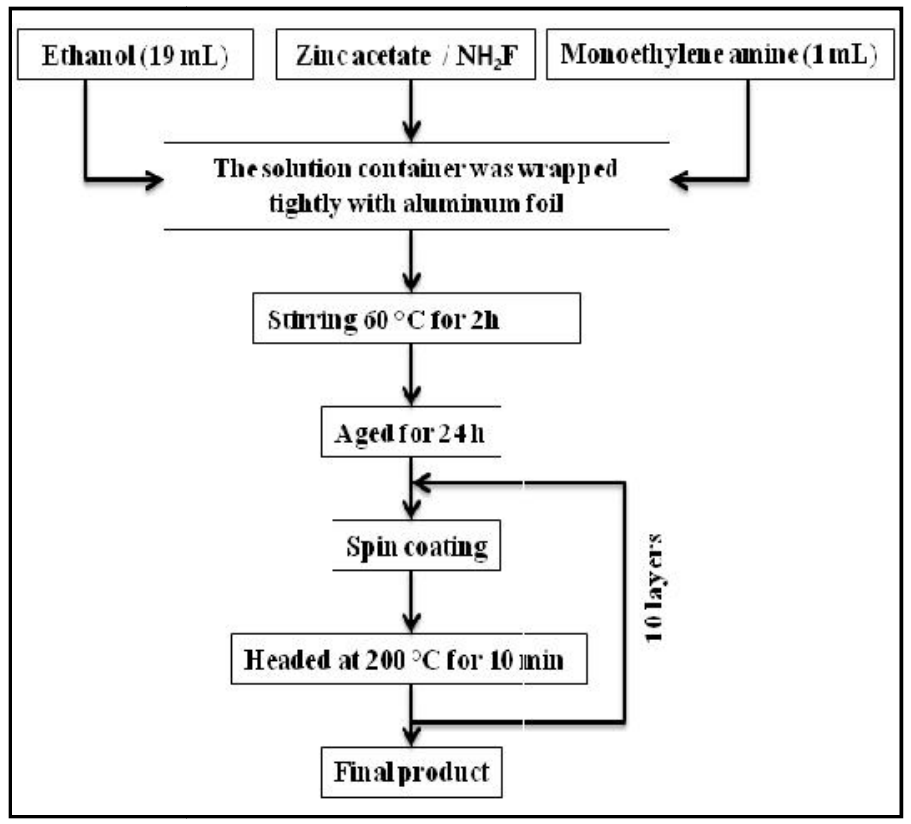

Figure 1 Flow chart of preparation of $\mathrm{ZnO}$ films by sol-gel technique

\section{CHARACTERIZATION TECHNIQUES}

The structural properties of the deposited films were analyzed with the help of XRD profiles obtained using Xray diffractometer (PANalytical PW 340/60 X'pert PRO). The optical studies were carried out using UV-vis-NIR double beam spectrophotometer (Perkin Elmer-Lambda 35 model). The surface morphological and electrical studies were carried out using scanning electron microscope (HITACHI S-3000 H) and four probe technique, respectively.

\section{RESULTS AND DISCUSSION}

\subsection{Chemistry of precursor solution}

The zinc acetate is added with ethanol solvent and it dispersed as $\mathrm{Zn}^{2+}$ ions and acetate. The low ionized nature of both $\mathrm{OH}^{-}$ions from the ethanol and $\mathrm{Zn}^{2+}$ ions from zinc acetate easily forms $\mathrm{Zn}(\mathrm{OH})_{2}$ in the stock solution. MEA acts as a stabilizer, the presence of amine increases the $\mathrm{pH}$ value which can encourage the formation of $\mathrm{Zn}(\mathrm{OH})_{2}$. During the deposition, each thin layer of $\mathrm{Zn}(\mathrm{OH})_{2}$ heated at $200{ }^{\circ} \mathrm{C}$ for $10 \mathrm{~min}$, which can give the sufficient thermal energy for covert from $\mathrm{Zn}(\mathrm{OH})_{2}$ to $\mathrm{ZnO}$. The clear mechanism of $\mathrm{ZnO}$ formation is given below:

$$
\begin{gathered}
\mathrm{C}_{2} \mathrm{H}_{3} \mathrm{OH}+\mathrm{C}_{4} \mathrm{H}_{10} \mathrm{O}_{6} \mathrm{Zn} \longrightarrow \mathrm{Zn}(\mathrm{OH})_{2}+\mathrm{C}_{2} \mathrm{H}_{3}+\mathrm{CH}_{3} \mathrm{COO}- \\
\operatorname{In}\left((\mathrm{OH})_{2} \stackrel{200{ }^{\circ} \mathrm{C}}{\longrightarrow} \mathrm{ZnO}+\mathrm{H}_{2} \mathrm{O}\right. \text { (vapour) }
\end{gathered}
$$

\subsection{Structural studies}

The sol-gel deposited film was confirmed as $\mathrm{ZnO}$ by the obtained XRD pattern compared with the standard JCPDS profile.
Figure 2 shows the XRD patterns of un-doped $\mathrm{ZnO}$ and $\mathrm{F}$ doped ZnO thin films. Several researchers reported that the sol-gel deposited films were in amorphous nature or power crystallinity before annealing at high temperatures [12]. Kumar et al. reported that the XRD pattern of the asprepared thin film exhibits amorphous nature, while the same films annealed at $700{ }^{\circ} \mathrm{C}$ have a hexagonal wurtzite structure and the increase in annealing time improved the crystal quality of the films [13]. But, in the present study, good crystalline $\mathrm{ZnO}$ films were obtained only at the preheat temperature of $200{ }^{\circ} \mathrm{C}$. In the case of un-doped $\mathrm{ZnO}$ film, the diffraction peak only at $34^{\circ}$ was observed. A strong diffraction peak at $34.4^{\circ}$ and two weaker peaks at $31.7^{\circ}$ and $36.2^{\circ}$ were observed for $\mathrm{F}$ doped film, indicting the reorientation of crystallite. Besides, no peaks associated to fluorine compounds were observed. The diffraction peaks at $31.7^{\circ}, 34.4^{\circ}$ and $36.2^{\circ}$ in the XRD patters could be indexed as (100), (002) and (101) plane of $\mathrm{ZnO}$, according to the JCPDS card no. 36-1451 [14]. For all films, the peak at $34.4^{\circ}$ shows the highest relative intensity, which indicated that the $\mathrm{ZnO}$ film has a preferred oriented along $\left(\begin{array}{lll}0 & 0 & 2\end{array}\right)$ plane. The mean crystallite size was calculated using Scherrer's formula

$$
D=\frac{0.9 \lambda}{\beta \cos \theta}
$$

Where, $\lambda$ is the wavelength of used X-ray (1.5406 $\AA$ ), $\beta$ is full width at half maximum (FWHM) and $\theta$ is Bragg's angle. The crystallite size of $\mathrm{ZnO}$ film is $21 \mathrm{~nm}$ and increased for $\mathrm{F}$ doped film. The calculated other structural parameter ' $c$ ' values are well fitted with the standard value (5.20661 Å) (Table 1).

Rajesh et al., 


\subsection{Optical studies}

The optical transmittance spectra of un-doped and $\mathrm{F}$ doped $\mathrm{ZnO}$ thin films were recorded as a function of wavelength in the range of $300-1100 \mathrm{~nm}$, as shown in Figure 3. Un-doped $\mathrm{ZnO}$ film exhibits the average transmittance around $93 \%$ in the visible region, where as the transmittance slightly decreases for the $\mathrm{F}$ doped films (91\%). The decrease in transmittance of doped films may be ascribed to scattering of photons at the grain boundaries and absorption of photon by defects in the films. The introduction of $\mathrm{F}$ atoms into the $\mathrm{ZnO}$ matrix remarkably deforms the crystal structure and forms more defects viz. oxygen vacancies and zinc interstitials. These intrinsic defects can generate more number of free electrons, which can decrease the transmittance by means of absorption of photons by the free electrons. The interference pattern of transmittance spectra is clearly indicating the smooth and uniform surface of the films. The characteristic absorption of $\mathrm{ZnO}$ shifts to higher energy as the $\mathrm{F}$ doping, indicating the widening of band gap value of the doped films. Optical band gap value of the films was calculated by Tauc's plot (inset Figure 3). The calculated band gap values are given in Table 1.

The band gap value of un-doped $\mathrm{ZnO}$ film is found to be $3.22 \mathrm{eV}$, this value is matched with reported literatures $[15,16]$. The obtained result shows the value of band gap increases for $\mathrm{F}$ doping. The increase in band gap value may be attributed to Moss Burstein effect caused by generation number of free electrons [17]. These films are more appropriate for the shorter wavelength applications in opto-electronic devices.

\subsection{Morphological studies}

The surface morphology of the films was carried out using SEM. SEM images of un-doped $\mathrm{ZnO}$ and $\mathrm{F}$ doped $\mathrm{ZnO}$ thin films are shown in Figure 4. It is observed that the surface morphology of the films is almost identical. The SEM images show the wrinkle surface; there is no remarkable variation in grains after $\mathrm{F}$ doping. Besides, the images consist of worm like network; each worm is interlinked by tiny threads.

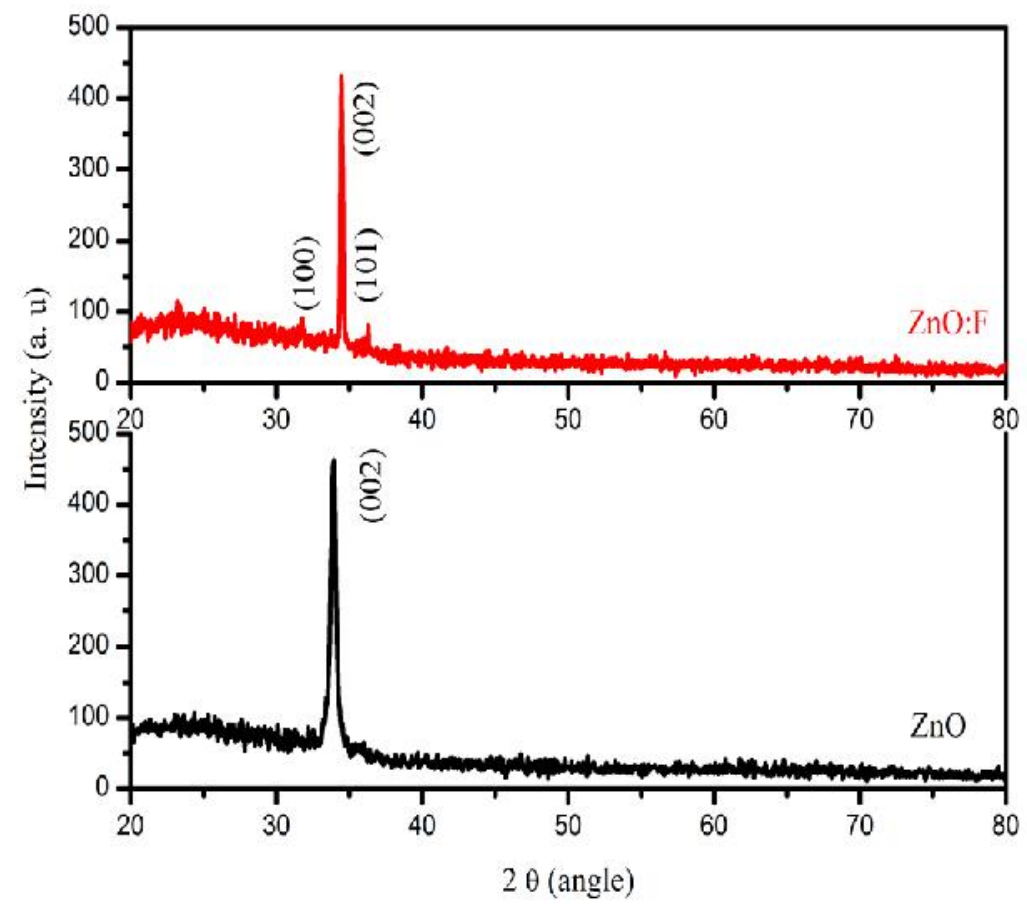

Figure 2 XRD pattern of $\mathrm{ZnO}$ and $\mathrm{F}$ doped $\mathrm{ZnO}$ thin films

Table 1 Structural parameters and band gap of $\mathrm{ZnO}$ and $\mathrm{F}$ doped $\mathrm{ZnO}$ thin films

\begin{tabular}{|c|c|c|c|}
\hline Sample & 'c' $(\AA)$ & Crystallite size (nm) & Band gap (eV) \\
\hline ZnO & 5.20801 & 21.8 & 3.23 \\
ZnO:F & 5.20749 & 24.6 & 3.24 \\
\hline
\end{tabular}

Rajesh et al., 


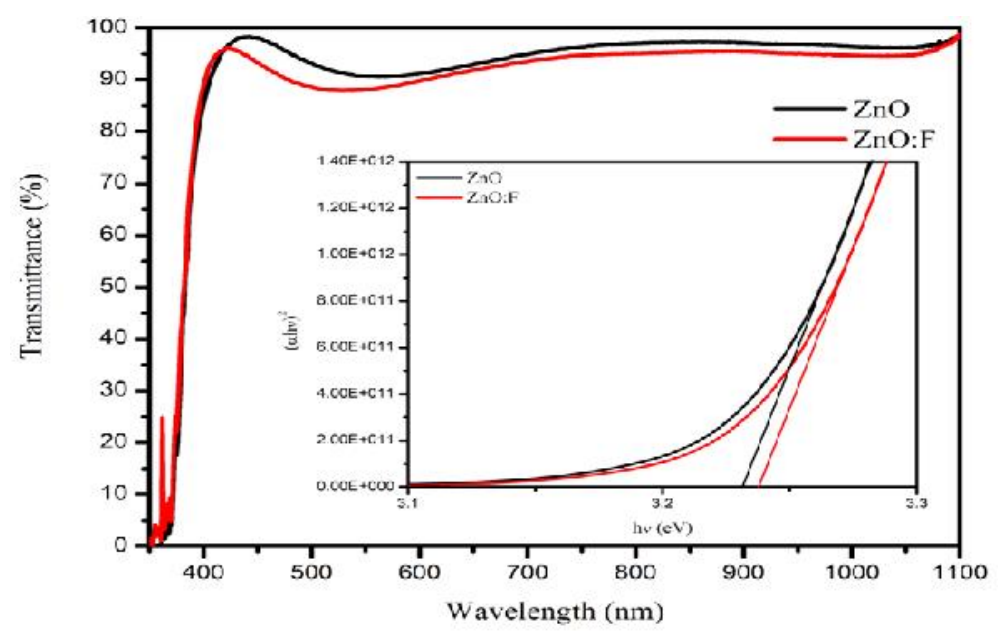

Figure 3 Transmittance spectra of $\mathrm{ZnO}$ and $\mathrm{F}$ doped $\mathrm{ZnO}$ thin films
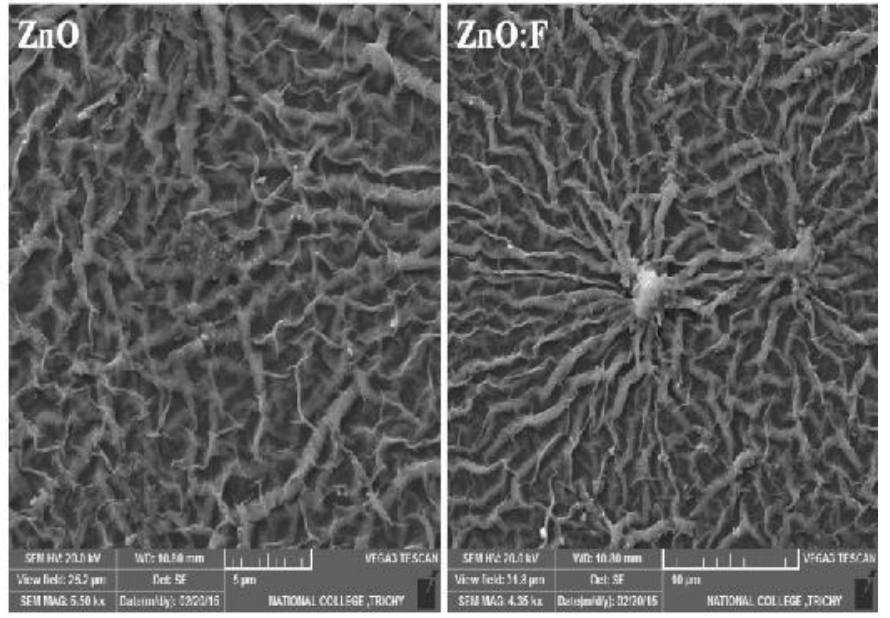

Figure 4 SEM images of ZnO and F doped ZnO thin films

\subsection{Electrical studies}

The electrical properties of un-doped and F doped $\mathrm{ZnO}$ films were measured using four probe technique. In the case of un-doped $\mathrm{ZnO}$ films, the electrical conductivity can be ascribed to point defects such as zinc interstitials and oxygen vacancies. Both defects generate number of free electrons into the $\mathrm{ZnO}$ lattice. The resistivity of un-doped $\mathrm{ZnO}$ film is $4.2 \Omega \mathrm{cm}$. The introduction of F- ions into the precursor solution reduces the resistivity to $1.4 \Omega \mathrm{cm}$ which can be due to generation of free electrons resulted

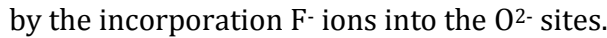

\section{CONCLUSION}

Un-doped $\mathrm{ZnO}$ and $\mathrm{F}$ doped $\mathrm{ZnO}$ thin films were successfully deposited on to the glass substrates; only at preheat temperature of $200^{\circ} \mathrm{C}$ by a sol-gel technique. The XRD studies clearly indicated that the $\mathrm{ZnO}$ films possess a hexagonal wurtzite crystal structure and the crystallite size decreased to $20 \mathrm{~nm}$ for $\mathrm{F}$ doped $\mathrm{ZnO}$ film. The optical transmittance spectra showed more than $90 \%$ transmittance in the visible region. The band gap energy value of the films increased from 3.23 to $3.24 \mathrm{eV}$ after $\mathrm{F}$ doping. Earth warms like wrinkle surface of the films was observed from the SEM images. The F doped (5 at. \%) ZnO film exhibits electrical resistivity $1.4 \Omega \mathrm{cm}$.

\section{ACKNOWLEDGEMENTS}

One of the authors Dr K. Saravanakumar thanks to DSTFIST-137/2013 for providing financial support to carry out part of this work.

\section{REFERENCES}

[1] Benramache, S., Temam, H.B., Arif, A., Guettaf, A., Belahssen, 0., 2014. Correlation between the structural and optical properties of Co doped $\mathrm{ZnO}$ thin films prepared at different film thickness. Optik. (125), 1816-1820.

[2] Caglar, Y., 2013. Sol-gel derived nanostructure undoped and cobalt doped $\mathrm{ZnO}$ : Structural,optical and electrical studies. J. Alloy Compnd. (560), 181188.

Rajesh et al., 
[3] Tarwal, N.L., Gurav, K.V., Kumar, T.P., Jeong, Y.K., Shim, H.S., Kim, I.Y., Kim, J.H., Jang, J.H., Patil, P.S., 2014. Structure, X-ray photoelectron spectroscopy and photoluminescence investigations of the spray deposited cobalt doped ZnO thin films. J. Anal. Appl. Pyrolysis. (106), 26-32.

[4] Zhao, S., Yan, K., Liu, Q., Yang, L., Huang, C., Zhao, K., Wang, A., 2013. Lateral photovoltaic effect observed in Co-doped ZnO film induced by $10.6 \mu \mathrm{m}$ infrared laser. Optik. (124), 1105-1107.

[5] Gürbüz, O., Güner, S., Büyükbakkal, O., Çalışkan, S., 2015. Structural, optical, and conducting properties of crystalline ZnO:Co thin films grown by reactive electron beam deposition. J. Magn. Magn. Mater. (373), 90-95.

[6] Zia, A., Ahmed, S., Shah, N.A., Anis-ur-Rehman, M., Khan, E.U., Basit, M., 2015. Consequence of cobalt on structural, optical and dielectric properties in ZnO nanostructures. Physica B. (473), 42-47.

[7] Mimouni, R., Boubaker, K., Amlouk, M., 2015. Investigation of structural and optical properties in Cobalt-Chromium co-doped $\mathrm{ZnO}$ thin films within the Lattice Compatibility Theory scope. J. Alloy Compnd. (624), 189-194.

[8] Anandhi, R., Mohan, R., Swaminathan, K., Ravichandran, K., 2012. Influence of aging time of the starting solution on the physical properties of fluorine doped zinc oxide films deposited by a simplified spray pyrolysis technique. Superlattices Microstruct. (51), 680-689.

[9] Ravichandran, K., Begum, N.J., Swaminathan, K., Sakthivel, B., 2013. Fabrication of a double layered FTO/AZO film structure having enhanced thermal, electrical and optical properties, as a substitute for ITO films. Superlattices Microstruct. (64), 185-195.

[10] Kumar, V., Singh, N., Mehra, R.M., Kapoor, A., Purohit, L.P., Swart, H.C., 2013. Role of film thickness on the properties of $\mathrm{ZnO}$ thin films grown by sol-gel method, Thin Solid Films. (539), 161165.

[11] Bu, I.Y.Y., 2014. Sol-gel production of wrinkled fluorine doped zinc oxide through hydrofluride acid. Ceram. Int. (40), 14589-14594.

[12] Vishwas, M., Narasimha Rao, K., Arjuna Gowda, K.V., Chakradhar, R.P.S., 2010. Effect of sintering on optical, structural and photoluminescence properties of $\mathrm{ZnO}$ thin films prepared by sol-gel process. Spectrochimica Acta Part A (77), 330-333.

[13] Kumar, V., Kumar, V., Som, S., Yousif, A., Singh, N., Ntwaeaborwa, O.M., Kapoor, A., Swart, H.C., 2014. Effect of annealing on the structural, morphological and photoluminescence properties of $\mathrm{ZnO}$ thin films prepared by spin coating. J. Colloid. Interface Sci. (428), 8-15.

[14] Rajkumar, P.V., Ravichandran, K., Baneto, M., Ravidhas, C., Sakthivel, B., Dineshbabu, N., 2015. Enhancement of optical and electrical properties of SILAR deposited $\mathrm{ZnO}$ thin films through fluorine doping and vacuum annealing for photovoltaic applications. Mater. Sci. Semicond. Process. (35), 189-196.

[15] Ashour, A., Kaid, M.A., El-Sayed, N.Z., Ibrahim, A.A., 2006. Physical properties of $\mathrm{ZnO}$ thin films deposited by spray pyrolysis technique. Appl. Surf. Sci. (252), 7844-7848.

[16] Kulandaisamy, A.J., Karthek, C., Shankar, P., Mani, G.K., Rayappan JBB, 2016. Room temperature ammonia sensing properties of $\mathrm{ZnO}$ thin films grown by spray pyrolysis: effect of $\mathrm{Mg}$ doping. Ceram. Int. (42), 1408-1415.

[17] Chen, L., Bi, X., 2008. Variations of microstructure, conductivity and transparency of Al-doped $\mathrm{ZnO}$ thin films prepared by radio frequency magnetron sputtering with target-substrate distances. Vacuum. (82), 1216-1219. under a Creative Commons Attribution-Non Commercial-ShareAlike 3.0 Unported License. 